\title{
La construcción del Estado social en México
}

doi: http://dx.doi.org/10.32870/espiral.v24i70.6597.g6044

Carlos Barba Solano

El Estado social en México. Un siglo de reformas hacia un sistema de bienestar excluyente fue escrito por Gerardo Ordoñez, en colaboración con Miguel Ángel Ramírez. El Dr. Ordoñez es profesor e investigador de El Colegio de la Frontera Norte, miembro del Sistema Nacional de Investigadores (SNI), nivel III, experto en políticas públicas, en particular en políticas sociales, y es actualmente coordinador del grupo "Pobreza y políticas sociales" del Consejo Latinoamericano de Ciencias Sociales (CLACSO). ${ }^{1}$

$\mathrm{Su}$ libro² (que es una edición conjunta de Siglo XXI Editores y El Colegio de la Frontera Norte) inicia y se inscribe en la colección La cuestión social, que se propone, entre otras cosas, inda-

I. Entre sus obras más recientes destacan los siguientes libros: Legalizing the City: Informal Settlements and Regularization Processes in Tijuana (Alegría y Ordoñez, 2016) y Diversidad vulnerada. Discriminación y política de protección del derecho a la igualdad en Baja California Sur (Ordoñez, 2012). También sobresalen una serie de libros que ha coordinado en colaboración con otros autores, entre ellos: Nueva ronda de reformas estructurales en México. ¿Nuevas políticas sociales? (Ordoñez y Valencia, 2016), editado en colaboración con Enrique Valencia en 2016, y Desafios de la pobreza para la agenda del desarrollo de México (Guillén y Ordoñez, 20I4), en conjunto con Tonatiuh Guillén, publicado en 2014.

2. El Estado social en México. Un siglo de reformas hacia un sistema de bienestar excluyente tiene como antecedente directo un libro escrito por Gerardo Ordoñez en 2002, publicado por la UNAM y ganador de un concurso de tesis de doctorado sobre el programa PROGRESA-SEDESOL.

Gerardo Ordoñez (20I7). El Estado social en México. Un siglo de reformas hacia un sistema de bienestar excluyente. México: Siglo XXI y El Colegio de la Frontera Norte. 
gar sobre los problemas sociales actuales y los cambios que enfrentan las sociedades contemporáneas condicionadas por incertidumbres económicas, desconfianza en la democracia y el debilitamiento del Estado, acentuando los casos de México y América Latina.

En concordancia con este proyecto, el objetivo del libro es, en palabras del autor:

reflexionar en torno a la importancia histórica y al proceso de construcción del sistema de bienestar [mexicano] que se originó hace cien años [...] [y] realizar un balance poniendo el acento en las reformas que han marcado el devenir de la política social en diferentes periodos de la historia, así como en los principales retos que aún persisten para culminar la construcción de un Estado de bienestar que garantice el pleno ejercicio de los derechos sociales a gran parte de la sociedad mexicana que aún permanece al margen de los beneficios del desarrollo (p. 9).

Se trata de un libro académico, ubicado en la tradición del pensamiento que ha estudiado el surgimiento, devenir y crisis del Estado benefactor. En él son considerados los debates históricos que se han desarrollado en el marco de las democracias occidentales sobre este tema. Sin embargo, su propósito específico es contribuir, a partir de la experiencia mexicana, al entendimiento del desarrollo y bienestar en América Latina al responder a la pregunta: ¿es el Estado de bienestar un proyecto viable en las sociedades capitalistas en desarrollo? Por ello, este libro está dirigido a investigadores, profesores y estudiantes interesados en varios temas relacionados entre sí: el desarrollo económico, la política social, la pobreza y la integración y cohesión social en América latina y específicamente en México (p. 10).

Para realizar esa tarea, el autor reconstruye el proceso de formación del Estado social mexicano a partir de la Constitución de 1917, que marcó el establecimiento de un Estado social de derecho, y hasta nuestros días. El trabajo considera 
sobre todo dos dimensiones básicas: una formal, referente a los cambios legislativos que establecen las obligaciones estatales en el campo del bienestar social, y la institucional, que se refiere a las organizaciones y los recursos públicos (humanos y financieros) involucrados en la realización de las reformas sociales. Una de las principales tesis sostenidas por el autor parte del reconstruir los nexos estructurales entre economía y reformas sociales que determinaron que la política social se convirtiera en una función secundaria, supeditada a las políticas y actividades económicas (p. 11).

Las fuentes utilizadas para realizar esta empresa incluyen una amplia bibliografía jurídica y académica, pertinente y actualizada, así como numerosas fuentes de datos de carácter estadístico. ${ }^{3}$ Tres temas destacan en esta revisión: el desarrollo, la constitución de regímenes de bienestar y el enfoque de derechos. La obra se divide en cuatro capítulos. El primero proporciona un marco de interpretación y tiene como eje la discusión de la intervención del Estado en el desarrollo social, el segundo analiza la formación del Estado social en México, el tercero se concentra en el análisis del combate a la pobreza en México, y el cuarto analiza y discute los principales desafíos para la consolidación del Estado de bienestar en dicho país. El libro cuenta, además, con una sección de anexos con información económica y demográfica sobre el gasto federal y el gasto social desde 1921 hasta 2014, así como una sección de siglas y acrónimos que facilitan la lectura del texto, que está de por sí escrito de manera ágil y amena.

El primer capítulo aborda la discusión que se ha generado en el ámbito internacional sobre el origen, las características y el proceso de expansión del Estado de bienestar en las sociedades capitalistas desarrolladas y democráticas

3. Más de trescientas cuarenta referencias bibliográficas, entre libros, capítulos de libro, artículos y documentos institucionales. 
a partir la Constitución de Weimar, de 1919, y sobre todo después de la posguerra de la Segunda Guerra Mundial, las cuales llevaron a la conformación de diferentes modelos de este tipo de Estado (más amplios o más restringidos, institucionales o residuales), concebidos como agentes del progreso social sobre bases democráticas, que se oponían al libre juego del mercado como fuerza única para lograr un buen funcionamiento de la economía y que impulsaron la creación de derechos y ciudadanía sociales (pp. 17-32).

En ese capítulo se discuten también las reformas parciales de las últimas tres décadas, en particular la contraofensiva neoconservadora a favor del libre mercado como fórmula para reactivar la iniciativa privada, la responsabilidad, la autonomía personal, la eficiencia y el ahorro, que eran presuntamente sofocados por el Estado de bienestar. Sin embargo, como señala el autor, la reforma contraofensiva no logró desmantelar el Estado de bienestar ni llevó a que este abandonara su rol como agente de desarrollo, aunque sí ha generado procesos sociales negativos como la precarización laboral y algunos recortes del gasto social y de los programas de tipo asistencial (pp. 32-37).

Este libro muestra también que la trayectoria ha sido muy distinta en el caso de los países en desarrollo, en donde se logró desarrollar amplios sistemas de protección, basados en sistemas de economía mixta, y en donde se realizaron importantes reformas sociales y agresivos programas de industrialización (aunque sin el componente democrático), como ocurrió en países como México, Brasil, Argentina y Chile. En estos casos, afirma el Dr. Ordoñez que la contrarreforma neoliberal ha generado cambios mucho más profundos que han debilitado la capacidad de las políticas sociales para hacer frente a las necesidades y desafíos de sus respectivas sociedades, que se expresan en mayor pobreza, desigualdad y exclusión (pp. 37-42). 
A pesar de ello, en el texto se subraya que, en los últimos años, a partir de cambios políticos que algunos autores han denominado como un giro a la izquierda, se han fortalecido posiciones que apoyan la intervención estatal en el ámbito laboral para reducir la pobreza y garantizar los derechos económicos, sociales y culturales, y que abren rutas de cambio hacia la construcción de sociedades menos desiguales y más integradas (pp. 43-44).

También en el primer capítulo, se percibe una ausencia sobre una discusión más profunda de dos temas: uno teórico, relativo a las diferencias existentes entre el "Estado social" y el "Estado de bienestar", y otro de carácter contextual, referente a la construcción y transformación de los regímenes de bienestar en América Latina y a la ubicación del caso mexicano dentro de ese marco. Sin embargo, esta ausencia no influye de manera determinante en el desarrollo de la obra.

El segundo capítulo analiza la formación del Estado social en México a partir de la promulgación de la Constitución de 1917. Ese Estado social abrió un amplio campo de intervención estatal en la economía, el trabajo y los servicios sociales, pero no en el ámbito de la política y los derechos sociales. El texto muestra que estos últimos empezaron a establecerse inicialmente en 1934 (educación primaria), pero debieron esperar hasta el periodo comprendido entre 1974 y 2012 para un amplio reconocimiento por parte del Estado (seguridad social, trabajo, salud, vivienda digna, educación media).

Para dar cuenta de este largo proceso, el autor despliega una periodización que incluye cuatro lapsos. El primero va de 1917 hasta el cardenismo, etapa en la que la política social fue poco desarrollada (pp. 45-60). El segundo periodo corresponde a la política social de la industrialización, comprendida entre 1940 y 1972, años en los que se despegó una compleja estrategia estatal para promover la industria, 
ampliar el mercado interno y proteger a los trabajadores formales con esquemas de seguridad social y de vivienda, mientras se instituían formas de asistencia social y de financiamiento de vivienda popular para las familias de los trabajadores del sector informal. En esos años creció significativamente el gasto social y se estableció un amplio conjunto de instituciones de protección social, marcadas por un profundo dualismo que condenó a una situación de virtual exclusión de la protección del Estado a amplios segmentos de la población, y particularmente a quienes se dedicaban a actividades tradicionales (pp. 60-64).

La tercera etapa se desarrolla entre los años de 1973 y 1982, y se refiere a la política del desarrollo rural, es decir, al conjunto de programas sociales que se establecieron para incluir a los trabajadores pobres del campo y para ampliar la cobertura de las instituciones de seguridad social a grupos desprotegidos, proceso que fue complementado con el establecimiento de un derecho universal al trabajo digno y socialmente útil y que parecía abrir la puerta de acceso universal a la seguridad social y el pleno empleo como políticas de Estado, aunque todo indica que se trató más de un proceso discursivo que de una ampliación real de la ciudadanía social, y que su auge quedó totalmente interrumpido por las crisis económicas de 1976 y 1982 (pp. 64-67).

El cuarto y último periodo inició en 1983 y aún está en marcha. Este periodo corresponde a la política social de la liberalización económica, estrategia sistemática que buscó redefinir la política social, lo que implicó el retiro o estancamiento de la participación pública en diversas áreas del bienestar social y supuso un cambio de óptica, cuyo eje fueron medidas compensatorias cada vez más focalizadas. Ordoñez indica que este enfoque estratégico fue mantenido y reforzado por los Gobiernos de la alternancia. El resultado de esta estrategia, nos dice el autor, ha sido excluyente, ya que sólo el $27 \%$ de la población goza en este momento 
de todos los bienes y servicios formalmente universales, mientras que el resto presenta diversos niveles de carencia en la garantía de sus derechos y el $46 \%$ se encuentran en la pobreza concebida en términos multidimensionales y, entre estos, casi el 10\% se encuentran en una situación de pobreza extrema.

El diagnóstico realizado en esta obra es claro: tras un siglo de desarrollo del Estado social mexicano, la sociedad está dividida por la desigualdad económica, y la política social favorece sólo a los individuos con mejor ubicación en la estructura económica, con ingresos más altos y con capacidad de organización e influencia en las decisiones gubernamentales (pp. 67-79).

El tercer capítulo, por su parte, se dedica a discutir el combate a la pobreza que ocupó el centro de la política social desde 1988. Esta sección inicia revisando los programas desarrollados durante la etapa final de la industrialización, vía sustitución de importaciones (conocida como desarrollo compartido), cuando el combate a la pobreza rural comenzó a ocupar un papel relevante en la política social a escala federal. En ella se toman en consideración varios programas, entre ellos, el PIDER (Programa de Inversiones para el Desarrollo Rural) y el Programa de Salud Asistencial Rural del IMSS, creados en 1973, y la COPLAMAR (Coordinación General del Plan Nacional de Zonas Deprimidas) y el SAM (Sistema Alimentario Mexicano), establecidos respectivamente en 1977 y 1980. En este apartado, se concluye que la operación de estos programas estuvo plagada de problemas y sus resultados fueron mínimos o francamente negativos (pp. 80-96).

En la segunda sección de este capítulo, se analizan los programas desarrollados durante la etapa de liberalización económica, en particular se analizan el PRONASOL (Programa 
Nacional de Solidaridad) y el PROGRESA-OPORTUNIDADES, ${ }^{4}$ el primero establecido en 1989 y el segundo en 1997, ambos con enfoques muy distintos.

PRONASOL le confirió un papel central a la pobreza urbana y dio continuidad al legado del PIDER y COPLAMAR, articulando medidas de apoyo a proyectos productivos, al bienestar social y al desarrollo regional, pero puso en marcha un modelo de organización y participación comunitaria inédito a través de la creación de numerosos comités de solidaridad. Se focalizó en la pobreza extrema y en la atención de grupos vulnerables (pueblos indígenas, campesinos, población en zonas semidesérticas y serranas, trabajadores agrícolas migratorios, habitantes de colonias populares en zonas urbanas, jóvenes, mujeres y niños). Se buscaba crear un piso social básico (en alimentación, salud, educación y vivienda) y se promovía la participación de Gobiernos municipales y estatales en el programa.

El autor subraya la dificultad de evaluar el programa PRONASOL debido a la inexistencia de fuentes de información sistemática y confiable y a la gran dispersión del programa, que incluía problemáticas muy complejas bajo su paraguas. Hay indicios de que el efecto fue significativo en las zonas urbanas, donde la pobreza se redujo, pero no en las rurales, donde aumentó. En todo caso, el autor señala que al final de su operación no había logrado restablecer las condiciones de vida previas a la crisis de 1982, y que el programa en la práctica funcionó de manera muy centralizada y con gran dispersión de objetivos (pp. 99-107).

El PROGRESA-OPORTUNIDADES, por su parte, reformado varias veces a partir de 2002, ha buscado operar evitando la dispersión de objetivos, maximizando los beneficios, buscando complementariedades entre las acciones estatales y corresponsabilidades de los beneficiarios y facilitando la 
gestión del programa. ${ }^{5}$ PROGRESA inició concentrando su acción contra la pobreza rural extrema, buscando potenciar las capacidades de los miembros de las familias en esta situación para ampliar sus oportunidades de alcanzar mejores niveles de bienestar, esto a través de la articulación de acciones en tres ámbitos: la educación, la salud y la alimentación (mediante apoyos monetarios entregados a las madres, servicios de salud y educativos, pláticas de salud y suplementos nutricionales).

A partir de 2002, el programa cambió de nombre a OPORTUNIDADES, amplió su población objetivo al ámbito urbano, extendió su cobertura a la educación de nivel medio superior, modificó sus criterios de focalización e incluyó nuevos apoyos monetarios (como el apoyo a adultos mayores o subsidios al consumo de energía), encaminados a mitigar los efectos de la crisis económica de 2007. En 2012, desplazó el centro de su acción de la inversión de la ruptura del ciclo intergeneracional de la pobreza a través de inversiones en capital humano a la búsqueda de mejores niveles de bienestar para toda la familia.

En su evaluación de este programa, el autor subraya aspectos positivos como el gran crecimiento de su cobertura sin incrementos notables en su costo, mejoras detectadas por numerosas evaluaciones en términos de su capacidad para romper con el ciclo intergeneracional de la pobreza extrema, mejoras en el desempeño y permanencia escolar de los beneficiarios, y también en materia de mortalidad materna e infantil y en el ámbito nutricional. También se mencionan estudios que ponen en tela de juicio algunos de estos logros, particularmente en cuanto al acceso a empleos de mayor calidad y mejor remunerados, lo que cuestiona su pretendido éxito en la ruptura de la reproducción interge-

5. Que implica el trabajo coordinado de sólo tres dependencias federales: la Secretaría de Educación, la Secretaría de Salud y el IMSS-Solidaridad. 
neracional de la pobreza. Finalmente, el autor señala que el entorno macroeconómico negativo de los últimos años, que ha implicado un repunte de la pobreza, pone en duda la eficacia de OPORTUNIDADES como vía para salir permanentemente de la pobreza (pp. 107-118). El autor concluye este capítulo señalando que los programas analizados no han demostrado ser capaces de reducir los niveles de pobreza de manera sostenida ni han logrado revertir los patrones de distribución social y territorial de la pobreza ni las condiciones de desigualdad entre regiones y grupos sociales.

Finalmente, en el capítulo cuarto se señala con claridad que el Estado de bienestar pasó de ser un proyecto nacional inacabado a ser un Estado deliberadamente limitado en cuanto a la definición de objetivos y alternativas para la inclusión social. El autor propone una serie de reformas para revertir esta situación, basadas en las propuestas de la Comisión Económica para América Latina y el Caribe (CEPAL) sobre cambio estructural para reducir la desigualdad y fortalecer el papel del Estado. Ordoñez recoge la recomendación de esta institución de asumir una visión de largo plazo y no adoptar un modelo único para lograr la universalización de la protección social y la creación de ciudadanía social en el ámbito del bienestar.

En el caso mexicano, el autor reconoce una serie de obstáculos que dificultan esta tarea: las debilidades estructurales de la economía, la estrechez de la política social, la erosión de la participación estatal en aspectos clave del bienestar social, las reformas neoliberales a los sistemas de pensiones, la segmentación del sistema de salud, y, en general, la subordinación de la política social a la política económica. Afirma que superar esos límites requiere de una estrategia compleja de reformas fundada en tres principios: universalidad, solidaridad, y eficiencia, a las que se suma la selectividad, cuando sea necesaria, para hacer más eficaz la universalización. Esto, nos dice, además de establecer prio-

\section{2}


ridades y un camino gradual, exige un nuevo pacto político nacional, tarea nada fácil pero que hay que emprender para avanzar en un proyecto alternativo de país (pp. 132-136).

$\mathrm{El}$ autor dedica el resto de este capítulo a discutir los temas que son cruciales para avanzar hacia un Estado de bienestar avanzado: por una parte, las políticas que inciden sobre el crecimiento, la creación de empleos de calidad y la reducción de desigualdades en la distribución del ingreso; por otra, las reformas de política social, que el autor identifica como prioritarias para cubrir vacíos y acercar los sistemas de bienestar al principio de universalidad. Esto sin duda es una de las grandes contribuciones de este libro al debate nacional sobre las vías para superar las grandes desigualdades, la pobreza, la exclusión, la desafiliación social que prevalecen en el país (pp. 139-177).

Por todo lo hasta ahora expuesto, recomiendo ampliamente la lectura de este libro.

Alegría, T., y Ordoñez G. (20I6). Legalizing the City: Informal Bibliografía Settlements and Regularization Processes in Tijuana. Tijuana: El Colegio de la Frontera Norte.

Guillén, T., y Ordoñez, G. (coords.) (20l4). Desafios de la pobreza para la agenda del desarrollo de México. México: El Colegio de la Frontera Norte, El Colegio de México. Ordoñez, G. (2002). La política social y el combate a la pobreza en México. México: UNAM. (20I2). Diversidad vulnerada. Discriminación y política de protección del derecho a la igualdad en Baja California Sur. Tijuana: El Colegio de la Frontera Norte. y Valencia, E. (coords.) (20I6). Nueva ronda de reformas estructurales en México. ¿Nuevas políticas sociales? Tijuana: El Colegio de la Frontera Norte. 